\title{
Retirement rigidities and the gap between effective and desired labour supply by older workers
}

\author{
Serena Trucchi ${ }^{1}$, Elsa Fornero ${ }^{2^{*}}$ and Mariacristina Rossi ${ }^{3}$
}

\author{
* Correspondence: elsa.fornero@ \\ unito.it \\ ${ }^{2}$ University of Turin, CeRP-Collegio \\ Carlo Alberto, Corso Unione \\ Sovietica, 218 Bis, 10134 Turin, Italy \\ Full list of author information is \\ available at the end of the article
}

\begin{abstract}
Our paper analyses the observed and desired labour supply by older workers and (recent) retirees in a country (Italy) with limited opportunities for flexible work schedules. To this purpose, we use a dataset drawn from the Bank of Italy's Survey on Household Income and Wealth providing information on desired and actual working hours. Our empirical analysis documents the gap between older individuals' desired and observed labour supply at both the extensive and the intensive margins and traces it back to gender, education and family composition. The paper provides useful insights into the potential usefulness of policies such as gradual retirement and part-time work in increasing older workers' employment.
\end{abstract}

Keywords: Retirement, Desired labour supply, Flexible retirement

JEL Classification: J26, J14

\section{Introduction}

Population ageing points to the need to increase the employment rate of older workers in order to guarantee both the sustainability of pension systems and the adequacy of resources in retirement. To achieve this goal, the main strategy of almost all European countries has consisted of increases in the statutory retirement age, the tightening of minimum requirements to access anticipated retirement and financial incentives to continue to work beyond the minimum (Eurofound 2016; European Commission 2015; OECD 2016). Although some countries (Italy among them) have established an automatic link between longevity and retirement age, the compulsory extension of working life is obviously not an ad libitum viable policy. This policy, moreover, reflects a rather traditional retirement scenario, typically characterised by full-time work ending abruptly in complete leisure. This pattern may not be what workers, or a significant proportion of them, want and may not necessarily serve firms' interests either. Concerning the first, who are the focus of our study, harsh discontinuity between working life and retirement, when the latter suddenly reduces working hours from full-time to zero, can indeed be regarded as a welfare-decreasing factor. If rigidities in both the pension system and the labour market prevent individuals from doing part-time work, workers may feel constrained to retire earlier than they would have done. People may

(c) The Author(s). 2018 Open Access This article is distributed under the terms of the Creative Commons Attribution 4.0 International License (http://creativecommons.org/licenses/by/4.0/), which permits unrestricted use, distribution, and reproduction in any medium, provided you give appropriate credit to the original author(s) and the source, provide a link to the Creative Commons license, and indicate if changes were made. 
prefer retirement to full-time work, but they may be willing to continue to work if they have access to a reduced effort level. Evidence on stated preferences for gradual retirement in the USA, based on an internet survey in 2005, shows that $38 \%$ of respondents aged 50 and over show interest in participating in partial retirement schemes (Brown 2005). Kantarci and van Soest (2008) present similar results for the Netherlands, where about $55 \%$ of working men aged between 51 and 65 years stated an interest in working part-time. Technological change, on its part, seems more favourable to flexibility than traditional productive methods. Policy interventions designed to foster flexibility in working schedules and to increase the possibility of combining a pension and work, with some sort of gradual retirement, would then be welfare-improving, without curbing firms' profitability.

Given workers' heterogeneity, investigating the characteristics of the people who would be better off if they had access to a smoother scheme of retirement is the first step in designing appropriate policies. In this paper, we look at preferences for hours of work expressed by older individuals, whether in employment or already retired, and compare them to their effective working hours (which may be zero in the case of full retirement). The analysis gives us an estimate of the 'discouraged' labour supply that older workers could instead deliver, as well as a picture of the characteristics of workers willing to work longer. It also provides an empirical basis for measures at both government and HR management levels directed at encouraging workers to postpone their retirement instead of forcing them to work full-time.

The literature on the desired labour supply is limited, perhaps because of the shortage of individual survey data eliciting this information. Some notable exceptions are Callan et al. (2009), Euwals and van Soest (1999) and van Soest et al. (2002), who use data on the preferred labour supply-respectively in Ireland and the Netherlands-to estimate labour supply, wage elasticities and the impact of tax reforms. van Soest and Vonkova (2014) exploit stated preferences collected by the Dutch CentER Panel about different hypothetical retirement trajectories with different ages of (partial or full) retirement and different replacement rates. They use the information to estimate parameters of the utility function in order to simulate the sensitivity of retirement decisions to financial incentives, showing substantial differences between results based on observed or desired labour supply.

Our paper adds to the literature and to the policy debate by documenting the gap between the preferred and observed number of working hours, at both the extensive and the intensive margins. To this end, we exploit an ad hoc section of the 2004 wave of the Italian Survey on Household Income and Wealth to ascertain the desired labour supply of both older workers and retirees. Our data testify to a 'displacement effect', limiting older workers' observed labour supply.

Descriptive evidence shows that a large majority of individuals aged 56-70 works the desired number of hours ( $85 \%$ of the sample). A non-negligible fraction of retirees, however, would like to work, most of them with a part-time schedule, and older workers declare that they are willing to continue to work, albeit with a lower intensity. The gap between the observed and desired labour supply is likely to depend on factors affecting the disutility of labour and the utility of additional resources. Our results confirm that gender, education and family composition are relevant factors associated with the desired labour supply. The comparison between the observed and the desired 
labour supply gives a measure of the severity of the displacement effect affecting older workers with respect to their level of work.

The paper is organised as follows. Section 2 provides an overview of part-time jobs and of rules for a more gradual retirement in Europe. Section 3 sketches the theoretical framework and Section 4 describes the institutional framework. Section 5 illustrates the data and the variables of interest. Section 6 comments on the empirical findings separately for retirees (Section 6.1) and for workers (Section 6.2). Section 7 concludes and discusses some policy implications of our results.

\section{Part-time work of older individuals and gradual retirement in Europe: an overview}

How much flexibility is there in Europe for working schedules at older ages? And where does Italy stand within this context? With $14 \%$ of older workers (55-65) formally engaged in part-time activities, Italy has the third lowest percentage of older part-timers in the EU, after Greece and Spain. The number of part-timers differs widely across countries, ranging from $7 \%$ in Greece to $49 \%$ in the Netherlands (Table 1). This gap suggests that differences in preferences can hardly be the only explanatory variable and that disincentives on the demand side as well as legal restrictions are likely to play a significant role. Providing evidence of the 'latent work supply' of older individuals (i.e. desired number of working hours in excess of the effective one) allows us to rule out the unavailability of older workers to perform part-time work as the main cause of the Italian discrepancy. A remarkable feature of European data is that where the overall incidence of part-time jobs is higher, the percentage of older workers engaged in such jobs is also higher. Conversely, where the incidence of part-time jobs is lower, this work is concentrated among the younger age groups. A tentative interpretation, which is beyond the scope of the present analysis, is that the latter situation gives an indication of precariousness, while the former suggests a better-performing labour market and more efficient retirement rules (Devicienti et al. 2016). More specifically, in countries where the market is more flexible and workers' preferences can be accommodated, the supply of part-time activities for older workers is higher than/equal to that of younger workers, suggesting that generally older workers prefer to keep working but not in a full-time capacity.

Part-time work at older ages can also be limited by legal restrictions to combine labour income and the cashing in of pension benefits. In extreme cases (which was the

Table 1 Incidence of part-timers across European countries (percentage points)

\begin{tabular}{lllllllllllllll}
\hline \multicolumn{1}{c}{} & $\mathrm{IT}$ & $\mathrm{FL}$ & $\mathrm{SW}$ & $\mathrm{NO}$ & $\mathrm{DK}$ & $\mathrm{GE}$ & $\mathrm{NL}$ & $\mathrm{UK}$ & $\mathrm{FR}$ & $\mathrm{ES}$ & $\mathrm{PO}$ & $\mathrm{GR}$ & EU 18 \\
\hline Age 55-64 & & & & & & & & & & & & & \\
Men & 6.7 & 13.4 & 12.6 & 13.2 & 11.4 & 10.9 & 25.4 & 16.1 & 11.3 & 4.4 & 12.2 & 4.5 & 10.5 \\
Women & 24 & 18 & 35.9 & 41.6 & 34.8 & 51.9 & 81.1 & 48.9 & 34.7 & 20.2 & 17.7 & 11.6 & 38.7 \\
Total & 13.8 & 15.8 & 23.9 & 26.7 & 22.4 & 30.2 & 49.2 & 31.2 & 23.1 & 11.4 & 14.8 & 7.3 & 23.4 \\
Age 15-64 & & & & & & & & & & & & & \\
Men & 8.2 & 10.0 & 13 & 14.9 & 16.8 & 9.4 & 26.2 & 11.3 & 7.4 & 7.6 & 6.8 & 6.9 & 9.4 \\
Women & 32.7 & 20.2 & 35.6 & 38.0 & 36.9 & 46.5 & 76.4 & 40.8 & 29.8 & 24.1 & 12.1 & 13.7 & 36.2 \\
\multicolumn{1}{l}{ Total } & 18.5 & 14.9 & 23.9 & 26 & 26.4 & 26.7 & 49.7 & 25.2 & 18.2 & 15.1 & 9.5 & 9.8 & 21.7 \\
\hline Source: Eurostat 2016 & & & & & & & & & & & &
\end{tabular}

Source: Eurostat 2016 
situation in Italy as well as in other European countries), official work after (anticipated or statutory) retirement age means a $100 \%$ taxation of pension benefits. In Italy, in particular, while the Defined Benefit formula to calculate the pension benefit effectively provided incentives to early retirement, the impossibility to work on a regular basis encouraged moonlight activities by older workers. In recent years, measures directed at supporting a more gradual retirement have often been advocated as a means to improve social welfare (without necessarily reducing the overall efficiency) by allowing workers to work (retire) more in accordance with their own preferences at older ages.

While gradual retirement on a large scale is still to come, various kinds of experiments have been carried out, generally consisting of the possibility of combining the accrued pension benefit (or a fraction of it) with work, either full- or part-time, and either with the same firm (phased withdrawal) or through a 'bridge job' with a new employer (partial retirement) (Brunello and Langella 2013; Kantarci and van Soest 2008). Various types of gradual retirement have been introduced and tested in different European countries, although the evidence regarding their success, in the sense of a consequent significant reduction of early withdrawals from labour matched by an increase in older workers' employment rate, is quite modest (Delsen 1996). Highlighting the main reasons behind this lack of popularity is beyond the scope of this paper. It may derive from inadequate demand for part-time labour-indeed, a major issue in several European countries (Brunello and Langella 2013; Kantarci and van Soest 2008) ${ }^{1}$-from inadequate labour supply by older workers and/or from institutional constraints (pension and labour market regulations). Our purpose here is to look at the discrepancy between the actual and the desired labour supply for older workers as a prerequisite for the effectiveness of policies directed at incentivising the employment rate of older people.

\section{Conceptual background}

A simple model provides the basic conceptual framework. Individuals are assumed to face the following inter-temporal maximisation problem, where utility depends upon consumption $(c)$ and leisure $(l)$ at each time from $t$ till the end of life $T$, supposed known.

$$
\max _{c_{t}, l_{t}} \sum_{s=t}^{T} u\left(c_{s}, l_{s}\right)
$$

The value function $V_{t}$ is then the inter-temporal utility at time $t$ when optimal choices are made:

$$
V_{t}=u\left(c_{t}^{*}, l_{t}^{*}\right) \beta u\left(c_{t+1}^{*}, l_{t+1}^{*}\right)+\ldots+\beta^{(T-t)} u\left(c_{T}^{*}, l_{T}^{*}\right)
$$

with $\beta$ indicating the subjective time discounting factor. Leisure can have values between 0 (i.e. full-time work) and $L$, which corresponds to not working: $0<l<L$. In the real world, leisure is not that flexible in its planning, as it is more likely that agents have to choose between working full-time and not working, the part-time option rarely being available. Let us focus our attention on the retirement period. After reaching the minimum requirement for retirement (age or age plus seniority), the worker can choose to withdraw and retire, or to engage in another year of (full-time) work. The trade-off implies that one additional year at work translates into higher resources in terms of 
present remuneration and future pension benefits, but lower immediate leisure. ${ }^{2}$ Retirement is assumed to be an irreversible choice. Workers will thus compare the two utilities under the two regimes. If the worker continues in (full-time) work after becoming eligible for a pension, the intertemporal (time separable) utility she faces is the following:

$$
V^{w}=u\left(c_{R}^{w}, 0\right)+\beta u\left(c_{R+1}^{w}, L\right) ; \ldots+\beta^{(T-R)} u\left(c_{T}^{w}, L\right) .
$$

If she decides to retire, the intertemporal utility is:

$$
V^{r}=u\left(c_{R}^{r}, L\right)+\beta u\left(c_{R+1}^{r}, L\right)+\ldots+\beta^{(T-R)} u\left(c_{T}^{r}, L\right)
$$

where $V^{w}$ is the utility in case of an extra year of work and $V^{r}$ is the utility in case of retirement. ${ }^{3} L$ is full-time leisure after retirement, while leisure is set to 0 during working life, since workers are constrained to work full-time (we abstract from unemployment spells). Superscripts in consumption $\left(c_{t}{ }^{w}\right.$ and $\left.c_{t}{ }^{r}\right)$ denote consumption in the two states, respectively, of employment and retirement. Consumption $c_{t}{ }^{w}$ is higher than $c_{t}{ }^{r}$, reflecting higher lifetime resources under the working regime compared to retirement. The chosen option will be the one providing the maximum utility. The individual will thus choose to postpone retirement if the following holds:

$$
V^{r}>V^{w}
$$

If a path of gradual retirement is offered, workers may choose this third option at time $R$, with $l^{w p t}<L$ denoting partial leisure due to part-time work. In this case, they get an indirect utility equal to:

$$
V^{w p t}=u\left(c_{R}^{w p t}, l_{R}^{w p t}\right)+\beta u\left(c_{R+1}^{w p t}, L\right)+\ldots \beta^{(T-R)}\left(c_{T}^{w p t}, L\right) .
$$

Gradual retirement would then be chosen if ${ }^{4}$ :

$$
V^{w p t}>V^{r}>V^{w}
$$

Knowing the preferred number of hours of work, we are thus able to detect if, and to what extent, there is room for more flexible working schedules which could improve workers' welfare. Our sample of interest is thus composed of people who are going to retire or have (recently) retired but would have preferred to stay at work under flexible working hours. Knowing the desired working hours and the actual working hours makes our analysis feasible.

\section{Institutional framework}

The choice between protracting work and retiring depends on various economic and institutional variables, shaping the environment in which the decision is taken and having to do with regulations in both the labour market and the pension system. These include the pension formula, which characterises the economic pros and cons of the decision and take into account the opportunities/constraints characterising the working career. In the case of a Defined Contribution (DC) with actuarial adjustments, the continuation of work is not penalised and the worker can freely decide according to her personal preferences, possibly mitigated by firm issues, on the one hand, and health status plus family considerations, on the other (Coda Moscarola et al. 2016). When the formula is, instead, of the Defined Benefit (DB) type, favouring steep earning profiles 
and partly independent of the total amount of paid contributions, the continuation of work generates an implicit tax on the pension wealth, because the increase in the pension benefit does not totally compensate for the additional contributions and the loss of 1 year of pension benefits. This kind of disincentive can be enough to induce workers to withdraw as soon as possible. Another important feature comes from the possibility of combining work and pension. DB pensions are typically associated with stricter limitations on work with respect to the DC ones. In the case of retirement as a binary choice, the worker is either engaged full-time or is a full-time retiree. The DC formula makes the combination of work and pension much easier, and in variable ways, by reducing or canceling the penalty for continuing work.

Since our data concern Italy in year 2004, we briefly summarise the situation in what follows. Retirement could be accessed at a relatively young age through so-called seniority pensions, allowing workers to retire after a minimum of 35 years of service, almost irrespective of age, on condition they do not continue to work (or work part-time for the self-employed). With respect to paid contributions, benefits were relatively generous, and this somewhat justified the no-earning condition for an employee or the limit to the self-employed. Restrictions on earnings were imposed even in the case of the (very rare) DC pensions. No restriction was applied in case of retirement at the statutory age (so-called old age pensions) or for seniority longer than 40 years. This rather strict regime, usually motivated by the consideration of encouraging the substitution of old workers with the young ones (the lump of labour fallacy' at work) started to change in 2001 and was completed in 2009, when the cashing in of the pension benefit and earning income from work were made compatible.

\section{Data}

The empirical analysis is based on the Bank of Italy's Survey on Household Income and Wealth (SHIW) and relies on data for the 2004 wave. The SHIW dataset is a representative sample of the Italian resident population and covers about 8000 households in each wave. It collects detailed information on household composition, income, wealth and the labour market status of the household members, including the number of worked weeks and average weekly working hours in the previous year. In addition, the 2004 wave includes questions to elicit the respondents' desired labour supply: more precisely, all the employed workers (employees, self-employed, members of a profession, family business, etc.) who were interviewed in person were asked the following question:

At the same hourly earnings, how many hours would you like to work on average per week?

Respondents who were not employed (unemployed, first job seekers, homemakers, retirees, etc.) reported whether they would be willing to work; if they answered 'yes', they were asked two additional questions: Considering the conditions generally obtainable nowadays, if [name] worked, given age, education and experience, would [name] be willing to accept: full-time payroll employment for the whole year/part-time payroll employment for the whole year/only occasional, seasonal or informal payroll employment/only freelance work or self-employment? 
How many hours a week would [name] like to work in this hypothetical job?

We use this information to construct an indicator of desired participation in the labour force (extensive margin) and to measure how many hours per week respondents would like to work (intensive margin). While it is clearly stated that wages for the hypothetical job are either current or market wages, the assumption that all other conditions (availability of child and elderly care, etc.) remain the same is implicit. In addition, nothing is explicitly stated about the possibility of gradual retirement, namely the possibility of combining part-time work with the cashing in of accrued pension benefits, nor about the value of future pension entitlements under different working choices (more specifically, whether the pension benefit will increase in accordance with an actuarially fair mechanism, or in a way that does not compensate for the additional contributions and the reduced retirement period, as implied by the then adopted DB formula). The assumption underlying our analysis is that respondents refer to the then current pension legislation which, as we have just seen, imposed restrictions on the possibility of combining labour income and retirement benefits. For the purpose of our analysis, we restrict our sample to individuals close to retirement age, namely those aged 55-70. Given that we want to focus on retirement choices as opposed to the continuation to work, we select individuals who are either still working or retired; we exclude from the sample those who are unemployed, homemakers and those on a different social insurance scheme (disability/survivor's/social pension). It is worth noting that while this sample selection is not a major issue for male workers, because men in this age range either work or are in a pre-retirement scheme or are retired, more caution is required in the case of women, given their much lower participation rate (around 40\%). After excluding from the sample cases in which the dependent variable has a missing value, we end up with 2670 observations, made up of 962 women and 1708 men. Figure 1 shows the distribution of workers and retirees by gender and age. In our sample, $77 \%$ of men and $87 \%$ of women are retired. ${ }^{5}$ The incidence of retirees obviously increases with age. This path is not linear, however, and we observe a sharp increase in the number of retired individuals around the typical retirement ages for private sector employees in 2004, which were 57 and 60 years, respectively, for women and men.

The regressors we use in our empirical analysis are factors that are likely to affect the disutility of work and the utility of additional resources, along with tastes and different attitudes towards participation in the labour market. We use as independent variables age and educational dummies, ${ }^{6}$, indicators for working (or having worked) as self-employed or in the private sector, total net wealth, variables for family composition (an indicator for being married or cohabiting with a partner; a dummy equal to one if the partner, if any, is working; the number of children living in the same or in another family) and two geographical indicators. Descriptive statistics are shown in Table 2. ${ }^{7}$

\section{Observed and desired labour supply}

In this section, we document whether, and to what extent, the effective labour supply differs from the desired one at the extensive and intensive margins. The possibility of looking at desired hours versus actual hours of work is allowed by the unique feature of our dataset where each respondent was asked the desired number of working hours. 


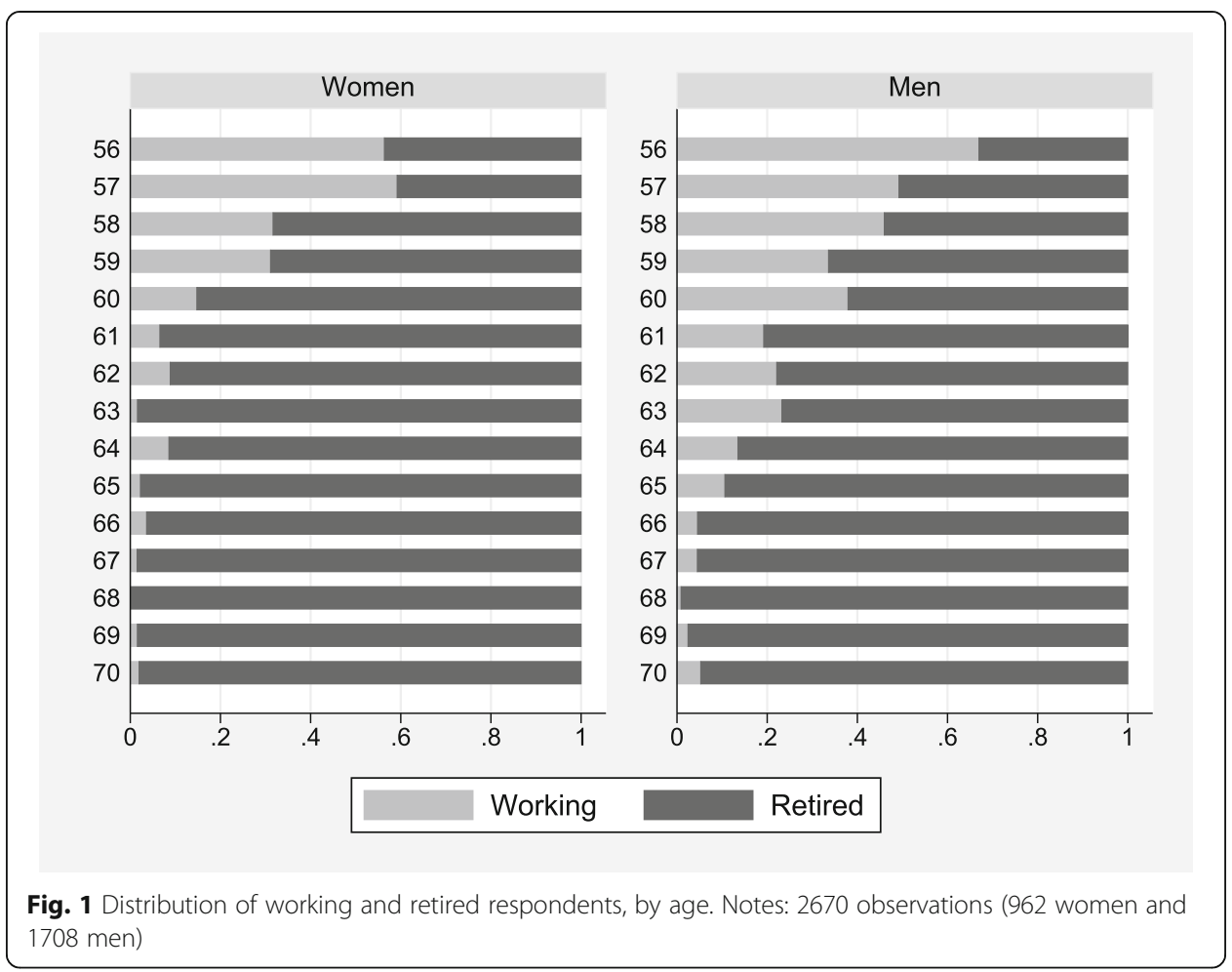

As anticipated in the introduction, the general picture reveals that approximately $85 \%$ of the sample is satisfied with the actual time devoted to work.

We first illustrate the desired participation and working hours of retirees (Section 6.1). In Section 6.2, we focus on the subsample of older workers and analyse the extent of the gap between their preferred and observed labour supply. To investigate whether preferences among older and younger workers differ, we also illustrate the desired labour supply for younger workers.

\subsection{Retirees}

A small but non-negligible fraction of retirees in our sample declares a willingness to work: respectively $7 \%$ of men and $3 \%$ of women. In order to describe their characteristics, we estimate the probability that retirees are willing to work. Probit estimate results are reported in Table 3 for the whole sample (column 1). Since the determinants of labour supply could be different across genders (Peri et al. 2015), we show the results for subsamples of women and men in columns 2 and 3, respectively.

Confirming the descriptive statistics, retired men are, on average, 4 percentage points more likely to be willing to work. Looking at the age distribution, we estimate a significant reduction by 8 percentage points in the willingness to work after the age of 65 for men, while we do not find any significant path for women. The desired participation of retirees turns out to be correlated with education. Men with a degree are 4.7 percentage points more likely to be willing to work, possibly reflecting a less physically demanding activity, higher attachment to the job and a substitution effect driven by higher wages (compared to less educated men). For women, the data point to a U-shaped effect of education: the desired participation is lowest for women with a high 
Table 2 Summary statistics

\begin{tabular}{lll}
\hline Variable & Mean & Std. dev. \\
\hline Age 61-65 & 0.339 & 0.474 \\
Age 66-70 & 0.33 & 0.47 \\
Medium educ. & 0.243 & 0.429 \\
High educ. & 0.273 & 0.446 \\
Self-employed & 0.17 & 0.375 \\
Private sector & 0.728 & 0.445 \\
Net wealth & 0.147 & 0.175 \\
Married/cohab. & 0.817 & 0.387 \\
No. children (in/out) & 1.83 & 1.238 \\
South & 0.252 & 0.434 \\
Center & 0.249 & 0.432 \\
\hline
\end{tabular}

Notes: 2670 observations

school degree and highest for those with a college degree. The desired participation of more highly educated women could reflect, along with the effect of high-paid and less physically intensive jobs, different family models and attitudes to work. Lower resources and pension benefits (linked to lower past wages) could explain the higher desired participation of less educated women compared to those with a secondary school education, by 1.5 percentage points. We estimate a positive coefficient for self-employment, while working in the public or private sector turns out to be insignificantly correlated with desired participation. We do not detect a significant effect of household wealth, while family composition plays a role. Married retired women are less likely to be willing to work than their single counterparts, possibly because they can rely on family resources (including survivors' benefits) to support consumption during retirement or because they are more involved in household chores. Looking at men, we do not find a significant difference between single and married men, though the latter turn out to be more prone to work if their partner is working. This finding is in line with the literature on joint retirement decisions, which shows that partners are likely to retire together (Banks et al. 2010), albeit the majority do not spend more time together, but rather synchronise their leisure (Stancanelli and van Soest 2012). Finally, we estimate that the number of children increases the desired participation of male workers. This result is consistent with the intention to leave a bequest or to help grown children through inter vivos transfers (Stark and Nicinska 2015), which are both common in Italy, where 80\% of individuals inherit or receive a house (or part of it). A further step to illustrate the desired labour supply of retirees is the analysis of the optimal intensity in their labour supply. Figure 2 illustrates the distribution of the preferred number of working hours that retirees are willing to offer. ${ }^{8}$ A large fraction of them would work less than the full-time schedule, with a mode of almost 30\% of retirees reporting 20-24 h per week (which is more than half the normal standard of 36). More than $25 \%$ would prefer to work less than $20 \mathrm{~h}$, while more than $70 \%$ would supply up to $30 \mathrm{~h}$ per week.

To illustrate which factors are associated with a greater desired intensity in the retirees' labour supply, we perform two complementary exercises. Firstly, we exploit information on the desired type of job and we estimate a multinomial logit model (Table 4); secondly, we use a Tobit model to estimate the number of working hours 
Table 3 Desired participation (probit), retired

\begin{tabular}{|c|c|c|c|}
\hline & All & Women & Men \\
\hline \multirow[t]{3}{*}{ Male } & $0.544^{* * *}$ & & \\
\hline & $(0.101)$ & & \\
\hline & {$[0.043]$} & & \\
\hline \multirow[t]{3}{*}{ Age 61-65 } & -0.067 & 0.385 & -0.173 \\
\hline & $(0.107)$ & $(0.282)$ & $(0.124)$ \\
\hline & {$[-0.006]$} & {$[0.014]$} & {$[-0.019]$} \\
\hline \multirow[t]{3}{*}{ Age $66-70$} & $-0.712^{* * *}$ & -0.468 & $-0.731^{* * *}$ \\
\hline & $(0.132)$ & $(0.357)$ & $(0.145)$ \\
\hline & {$[-0.056]$} & {$[-0.015]$} & {$[-0.078]$} \\
\hline \multirow[t]{3}{*}{ Medium educ. } & -0.090 & $-0.659^{* *}$ & 0.060 \\
\hline & $(0.150)$ & $(0.296)$ & $(0.177)$ \\
\hline & {$[-0.007]$} & {$[-0.015]$} & {$[0.007]$} \\
\hline \multirow[t]{3}{*}{ High educ. } & $0.438^{* * *}$ & $0.812^{* * *}$ & $0.349^{*}$ \\
\hline & $(0.159)$ & $(0.296)$ & $(0.185)$ \\
\hline & {$[0.046]$} & {$[0.047]$} & {$[0.047]$} \\
\hline \multirow[t]{3}{*}{ Self-employed } & $0.281^{* *}$ & 0.452 & $0.286^{*}$ \\
\hline & $(0.134)$ & $(0.289)$ & $(0.153)$ \\
\hline & {$[0.029]$} & {$[0.022]$} & {$[0.039]$} \\
\hline \multirow[t]{3}{*}{ Private sector } & -0.033 & -0.183 & -0.003 \\
\hline & $(0.116)$ & $(0.251)$ & $(0.135)$ \\
\hline & {$[-0.003]$} & {$[-0.007]$} & {$[-0.000]$} \\
\hline \multirow[t]{3}{*}{ Net wealth } & -0.006 & -0.506 & 0.200 \\
\hline & $(0.266)$ & $(0.679)$ & $(0.266)$ \\
\hline & {$[-0.001]$} & {$[-0.017]$} & {$[0.023]$} \\
\hline \multirow[t]{3}{*}{ Married/cohab. } & $-0.514^{* * *}$ & $-0.933^{* * *}$ & -0.213 \\
\hline & $(0.122)$ & (0.193) & $(0.181)$ \\
\hline & {$[-0.059]$} & {$[-0.056]$} & {$[-0.028]$} \\
\hline \multirow[t]{3}{*}{ No. children (in/out) } & $0.106^{* * *}$ & 0.074 & $0.107^{* * *}$ \\
\hline & $(0.034)$ & $(0.074)$ & $(0.039)$ \\
\hline & {$[0.009]$} & {$[0.003]$} & {$[0.012]$} \\
\hline \multirow[t]{3}{*}{ South } & -0.017 & $-0.739^{* *}$ & 0.130 \\
\hline & $(0.118)$ & $(0.304)$ & $(0.135)$ \\
\hline & {$[-0.001]$} & {$[-0.016]$} & {$[0.016]$} \\
\hline \multirow[t]{3}{*}{ Center } & 0.180 & -0.059 & $0.273^{* *}$ \\
\hline & $(0.111)$ & $(0.227)$ & $(0.132)$ \\
\hline & {$[0.017]$} & {$[-0.002]$} & {$[0.035]$} \\
\hline \multirow[t]{2}{*}{ Constant } & $-1.681^{* * *}$ & $-1.398^{* * *}$ & $-1.489^{* * *}$ \\
\hline & $(0.198)$ & $(0.366)$ & $(0.236)$ \\
\hline
\end{tabular}

Notes: Observations: 2142 (834 women and 1308 men). The table shows the estimated coefficients; standard errors are in round brackets and marginal effects in squared brackets; other variables are at their mean value $* p<0.1 ; * * p<0.05 ; * * * p<0.01$

desired by retirees (Table 5). Table 4 reports estimate results for a multinomial logit model, estimated on the sample of retirees who are willing to work. Potential outcomes for the desired job are working full-time, working part-time, working occasionally, and 


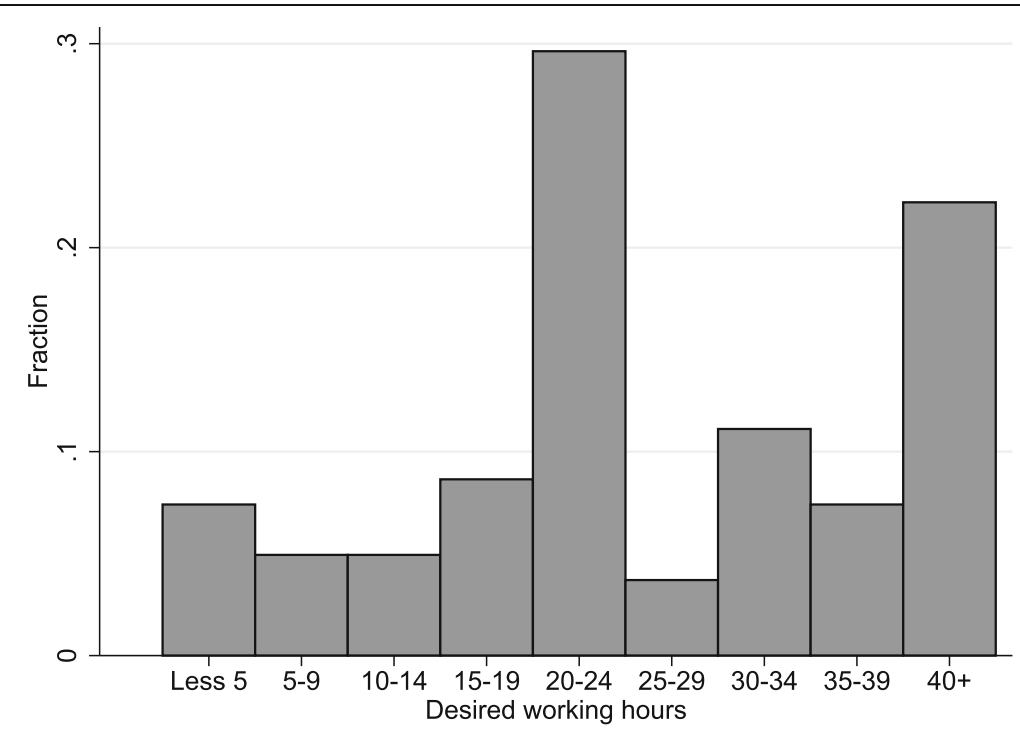

Fig. 2 Distribution of desired intensity for retirees who would like to work. Notes: 81 observations

Table 4 Type of job, retirees willing to work. Multinomial logit

\begin{tabular}{lllll}
\hline & Full-time & Part-time & Occasional & Self-empl. \\
\hline Male & 0.010 & -0.228 & 0.185 & 0.033 \\
& $(0.057)$ & $(0.126)^{*}$ & $(0.134)$ & $(0.104)$ \\
Age 61-65 & 0.031 & -0.050 & 0.089 & -0.070 \\
Age 66-70 & $(0.048)$ & $(0.096)$ & $(0.101)$ & $(0.084)$ \\
& $-0.681^{* * *}$ & $0.324^{* *}$ & $0.357^{* *}$ & 0.000 \\
Medium educ. & $(0.248)$ & $(0.147)$ & $(0.161)$ & $(0.151)$ \\
& 0.037 & $0.368^{* * *}$ & -0.169 & $-0.236^{* *}$ \\
High educ. & $(0.041)$ & $(0.105)$ & $(0.124)$ & $(0.095)$ \\
& 0.004 & $-0.344^{* * *}$ & 0.025 & $0.316^{* * *}$ \\
Self-employed & $(0.032)$ & $(0.129)$ & $(0.138)$ & $(0.118)$ \\
& 0.007 & -0.147 & $-0.293^{* *}$ & $0.433^{* * *}$ \\
Private sector & $(0.056)$ & $(0.139)$ & $(0.140)$ & $(0.101)$ \\
& 0.052 & -0.061 & -0.021 & 0.030 \\
Net wealth & $(0.073)$ & $(0.093)$ & $(0.102)$ & $(0.088)$ \\
& -0.185 & -0.264 & 0.147 & 0.302 \\
Married/cohab. & $(0.296)$ & $(0.301)$ & $(0.282)$ & $(0.197)$ \\
& -0.008 & 0.008 & -0.156 & 0.157 \\
No. children (in/out) & $(0.064)$ & $(0.160)$ & $(0.136)$ & $(0.135)$ \\
& 0.001 & -0.002 & 0.010 & -0.009 \\
South & $(0.015)$ & $(0.046)$ & $(0.043)$ & $(0.051)$ \\
& 0.028 & 0.114 & -0.025 & -0.116 \\
Center & $(0.056)$ & $(0.107)$ & $(0.111)$ & $(0.107)$ \\
& 0.019 & -0.119 & 0.122 & -0.022 \\
& $(0.063)$ & $(0.101)$ & $(0.096)$ & $(0.084)$ \\
\hline
\end{tabular}

Notes: Observations: 120

$* p<0.1 ; * * p<0.05 ; * * * p<0.01$ 
Table 5 Desired working hours (Tobit), retired

\begin{tabular}{|c|c|c|c|}
\hline & & Women & Men \\
\hline \multirow[t]{2}{*}{ Male } & $3.242^{* * *}$ & & \\
\hline & $(0.846)$ & & \\
\hline \multirow[t]{2}{*}{ Age 61-65 } & -0.731 & 1.508 & -1.668 \\
\hline & $(0.889)$ & $(0.982)$ & -1.053 \\
\hline \multirow[t]{2}{*}{ Age 66-70 } & $-5.210^{* * *}$ & -1.621 & $-0.516^{* * *}$ \\
\hline & (1.239) & -1.728 & (1.388) \\
\hline \multirow[t]{2}{*}{ Medium educ. } & 0.569 & -1.797 & 1.549 \\
\hline & -1.170 & -1.233 & -1.342 \\
\hline \multirow[t]{2}{*}{ High educ. } & $2.473^{*}$ & $3.403^{* *}$ & 1.843 \\
\hline & $(1.272)$ & $(1.412)$ & -1.451 \\
\hline \multirow[t]{2}{*}{ Self-employed } & $3.326^{* * *}$ & $2.645^{* *}$ & $3.432^{* * *}$ \\
\hline & $(1.126)$ & $(1.284)$ & $(1.154)$ \\
\hline \multirow[t]{2}{*}{ Private sector } & -0.344 & -0.076 & -0.536 \\
\hline & $(0.973)$ & -1.184 & -1.110 \\
\hline \multirow[t]{2}{*}{ Net wealth } & -0.618 & $-6.881^{* *}$ & 2.324 \\
\hline & -2.426 & (3.143) & -2.082 \\
\hline \multirow[t]{2}{*}{ Married/cohab. } & $-2.760^{* * *}$ & $-3.158^{* * *}$ & -0.016 \\
\hline & $(0.974)$ & $(0.685)$ & -1.632 \\
\hline \multirow[t]{2}{*}{ No. children } & $0.754^{* * *}$ & 0.370 & $0.728^{* *}$ \\
\hline & $(0.267)$ & $(0.334)$ & $(0.314)$ \\
\hline \multirow[t]{2}{*}{ South } & -0.162 & $-23.496^{* * *}$ & 1.317 \\
\hline & $(0.982)$ & $(4.898)$ & -1.086 \\
\hline \multirow[t]{2}{*}{ Center } & 0.510 & -0.265 & 0.934 \\
\hline & $(0.962)$ & $(0.917)$ & -1.115 \\
\hline
\end{tabular}

Notes: Observations: 2103 (827 women and 1276 men). Dummies for macro-areas are also included. The table shows the marginal effects on $E(\mathrm{dh} \mid \mathrm{dh}>0)$, where $\mathrm{dh}$ is the number of desired hours. Other variables are at their mean value $* p<0.1 ; * * p<0.05 ; * * * p<0.01$

self-employment/freelance only. Older retirees (aged 66-70) are less prone to work full-time and prefer part-time or occasional jobs. Education level is correlated with the probability of being self-employed, as opposed to part-time jobs. Those with a high and low level of education are, respectively, the most and least likely to choose self-employment. This is possibly correlated with different types of jobs within the broad category of self-employment, more likely related to consultancy or professional advice for people with a degree, and to manual jobs for respondents with a low level of schooling. Finally, people who were self-employed declared that they preferred to remain in this type of employment. Table 5, based on Tobit estimate results, shows the effect of covariates on desired intensity, given that the desired number of working hours is positive. As expected, retirees older than 65 would work $5 \mathrm{~h}$ fewer than younger respondents, this relationship being significant only for men. Highly educated women would like to work more, possibly because of different types of jobs and their attachment to the labour force. Family composition affects the intensity of the labour supply, mirroring its impact on the extensive margin. Married women would work, on average, $3 \mathrm{~h}$ per week fewer than single women, while having children increases the labour supply of retired men. Finally, household wealth has a negative effect on desired 
intensity in the female labour supply, which is in line with recent literature showing a positive impact of wealth on the labour supply (Brown et al. 2010; Cesarini et al. 2015; Picchio et al. 2017).

\subsection{Workers}

We now turn to the description of the desired labour supply of respondents who are still in the labour force. The distribution of observed and desired working hours is shown in Fig. 3. On average, older workers work $40 \mathrm{~h}$ per week, while they would like to offer fewer than $37 \mathrm{~h}$. The weekly working hours are 40 or more hours for almost $60 \%$ of these workers, while fewer than $50 \%$ would like such an intensity; the gap between observed and desired hours is even larger if we consider a working schedule of at least $45 \mathrm{~h}$ per week, the percentages being, respectively, 27 and 15\%. About 40\% would work only a few hours less than the full-time schedule (30-39 h), and 6.5\% would work part-time (20-24 h). The differences between observed and desired working hours, for the whole sample and by gender, are shown, respectively, in Figs. 4 and 5. Positive values in those graphs reflect situations where the respondent works more hours than s/he would like to. About half of the workers are satisfied; almost $40 \%$ work more than their optimal level, and for half of them, the gap between observed and desired intensity in the labour supply is larger than $10 \mathrm{~h}$ per week. Finally, we estimate the extent to which desired working hours vary according to household and individual characteristics. Table 6 reports OLS estimates, where the dependent variable is the desired intensity of workers' labour supply. ${ }^{9}$

We use two samples (55-70 and 50-70, respectively) for the whole population and for men only. Men want to work more than women, a little more than $1.5 \mathrm{~h}$. However, the extra hour worked causes an extra burden for just a little more than half an hour. Indeed only $0.4 \mathrm{~h}$ is desired for one extra hour of work observed for the older sample

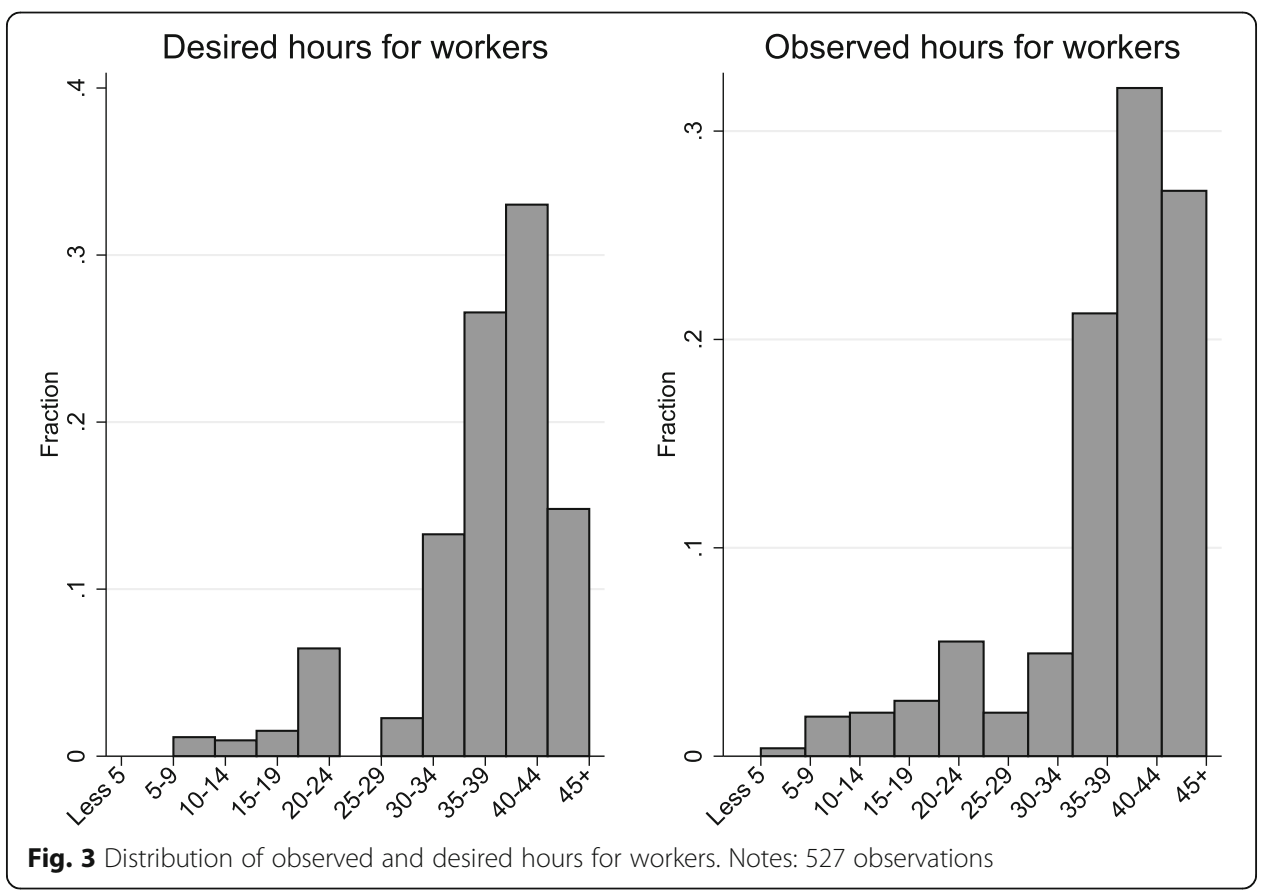




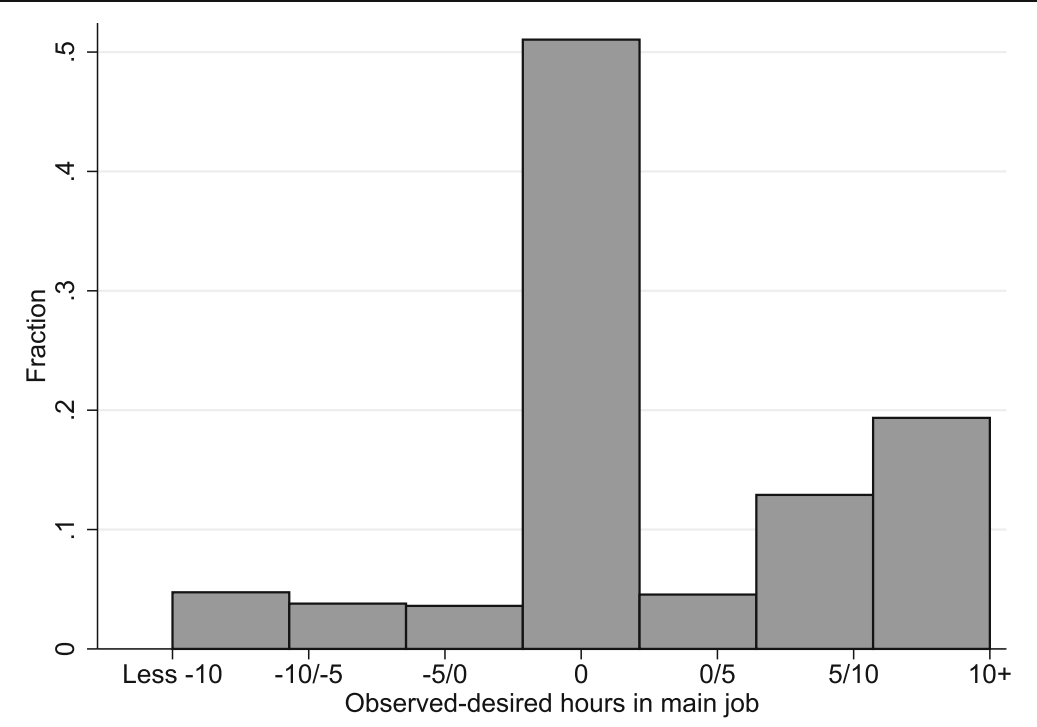

Fig. 4 Distribution of difference between observed and desired hours for workers. Notes: 527 observations

(55-70). When we include those aged between 50 and 55, we notice that people dislike less the extra hour worked ( 0.5 being the coefficient of observed hours versus 0.4 for the older sample in column 1). Focusing on men only, we notice that in some cases the male sample shows a more pronounced effect of significant coefficients such as being married. Married men would like to work two additional hours, highlighting the possible household head effect and family supporting role. The number of desired working hours turns out to be greater for less educated workers, private sector employees, married respondents and those living in northern regions.

Finally, we compare our results for workers around retirement with those for younger workers. Estimate results for the sample of workers aged 30-50 years are reported in Table 7. The general picture holds across differently aged workers. Young men who work would like, on average, to work additional $2 \mathrm{~h}$. However, the extra hour actually worked causes a heavier burden for the younger than for the older workers, the coefficient of the observed hours indicating that for each hour worked, less than half an hour would be the preferred time devoted to work ( 0.4 of an hour). When the sample is split by gender, men clearly show the highest burden of working 'too much' in relation to their optimal (desired) hours, which are a third of those actually worked.

\section{Conclusions}

This paper examines the observed and desired labour supply of Italian people close (on both sides) to retirement age and identifies the individuals who suffer a larger discrepancy of their effective labour supply in comparison to its preferred level. Our analysis shows that a somewhat relevant proportion of retirees $3 \%$ and $7 \%$ for women and men, respectively) would be willing to work. We distinguished between workers and retirees. As for the latter group, men are, on average, more willing to work than women. A college degree is associated with a higher desired labour supply, both at the extensive and at the intensive margins. Further, family composition affects the desired retirees' labour supply, but differently for men and women and according to marital status. 


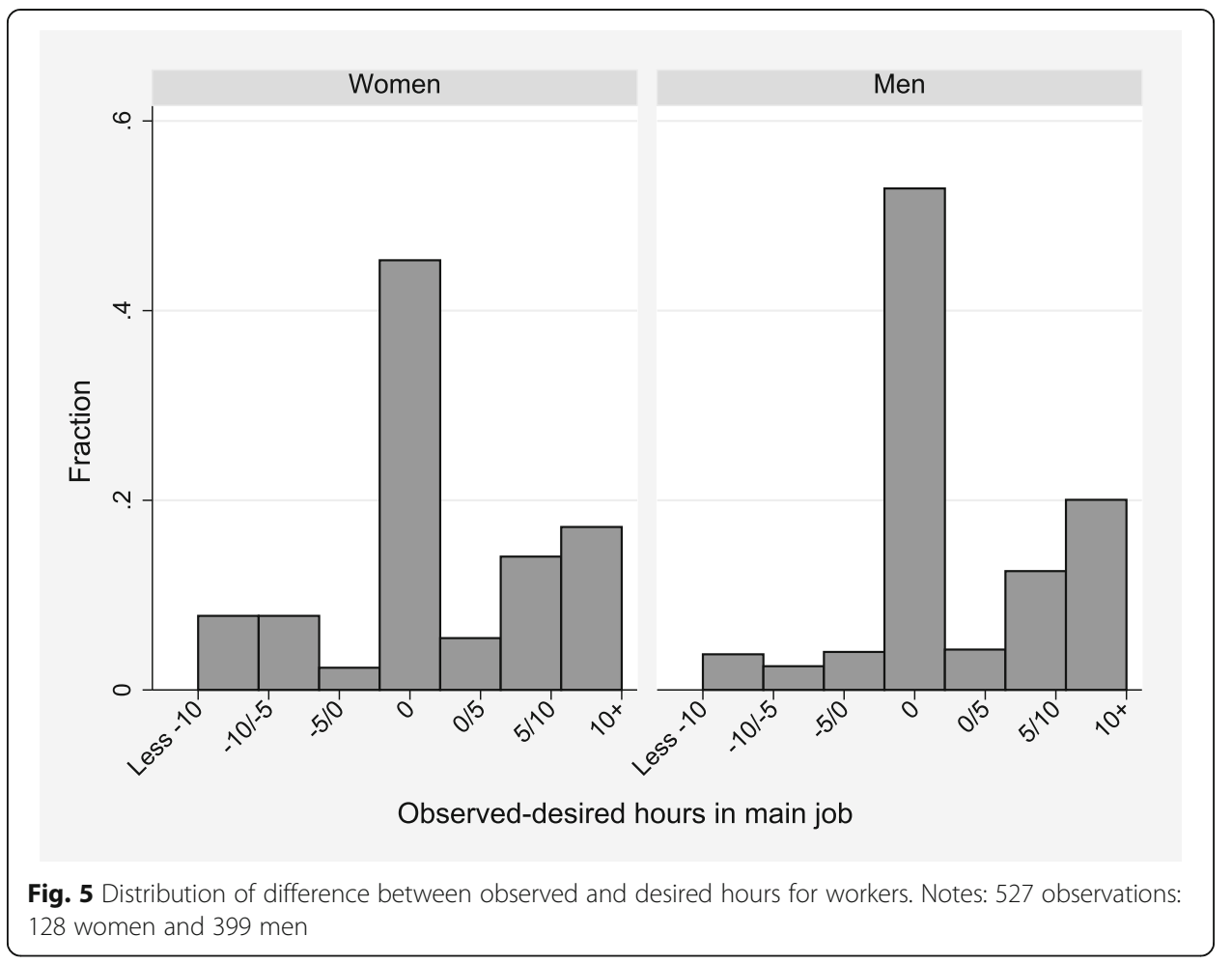

Married women would like to work less than those who are single, while men's favourite participation in the labour market turns out to be higher when their wife is still working, in line with the complementarity hypothesis in the retirement decision of couples. Finally, retired men with children are more willing to work than men without offspring.

Turning to (older) workers, their favourite labour supply is, on average, smaller than the actual hours worked, indicating a preference for reduced labour activity. This result is consistent with a more general sentiment of lower desired hours of work, which emerges also for younger workers. Indeed, preference for working less hours dominates at any age among workers.

The evident discrepancy between the observed and desired labour supply suggests that labour and retirement policies do not accommodate the preferred working pattern of older individuals. However, while promoting flexibility in working trajectories at the end of the working life can improve the welfare of workers whose labour supply is constrained to be zero at retirement, the overall effect on the total working hours is less straightforward. Some workers who indicated a preference for part-time work would otherwise have retired completely, but others would have kept working full-time, the total effect on the labour supply depending on which of the two effects dominates. However, as pointed out by Kantarci and van Soest (2008), 'previous studies that make the quantitative trade-off of the negative and positive labour supply effects unambiguously conclude that the positive effects dominate: creating more opportunities for gradual retirement can lead to an increase in total labour supply'. Along with an impact on the labour force participation of the older population, promoting flexibility in exiting the labour market has other effects. Firstly, it can increase job satisfaction and utility of workers at the end of their career by allowing them to work at an intensity that is closer to their preferred one. Secondly, gradual retirement schemes could 
Table 6 Desired working hours, workers

\begin{tabular}{|c|c|c|c|c|}
\hline & \multicolumn{2}{|l|}{ Age 55-70 } & \multicolumn{2}{|l|}{ Age 50-70 } \\
\hline & All & Men & All & Men \\
\hline \multirow[t]{2}{*}{ Male } & $1.589^{* *}$ & & $1.680^{* * *}$ & \\
\hline & $(0.775)$ & & $(0.454)$ & \\
\hline \multirow[t]{2}{*}{ Hours worked } & $0.434^{* * *}$ & $0.438^{* * *}$ & $0.490^{* * *}$ & $0.446^{* * *}$ \\
\hline & $(0.044)$ & $(0.056)$ & $(0.031)$ & $(0.040)$ \\
\hline \multirow[t]{2}{*}{ Wage } & -0.018 & -0.043 & -0.013 & -0.027 \\
\hline & $(0.047)$ & $(0.047)$ & $(0.029)$ & $(0.030)$ \\
\hline \multirow[t]{2}{*}{ Age 56-60 } & & & 0.674 & 0.589 \\
\hline & & & $(0.435)$ & $(0.499)$ \\
\hline \multirow[t]{2}{*}{ Age 61-65 } & -0.018 & 0.405 & 0.374 & 0.871 \\
\hline & $(0.643)$ & $(0.770)$ & $(0.633)$ & $(0.742)$ \\
\hline \multirow[t]{2}{*}{ Age 66-70 } & -0.205 & -0.853 & 0.468 & -0.395 \\
\hline & $(1.460)$ & $(1.751)$ & (1.328) & $(1.613)$ \\
\hline \multirow[t]{2}{*}{ Medium educ. } & 1.273 & 0.360 & $1.266^{* *}$ & 0.719 \\
\hline & $(0.818)$ & $(0.973)$ & $(0.526)$ & $(0.608)$ \\
\hline \multirow[t]{2}{*}{ High educ. } & $-1.544^{*}$ & -0.712 & $-1.480^{* * *}$ & -0.780 \\
\hline & $(0.867)$ & $(1.023)$ & $(0.571)$ & $(0.656)$ \\
\hline \multirow[t]{2}{*}{ Self-employed } & -0.310 & -0.648 & -0.534 & -0.647 \\
\hline & $(0.784)$ & $(0.844)$ & $(0.543)$ & $(0.612)$ \\
\hline \multirow[t]{2}{*}{ Private sector } & $1.536^{* *}$ & $1.914^{* *}$ & $1.329^{* * *}$ & $1.449^{* * *}$ \\
\hline & $(0.700)$ & $(0.776)$ & $(0.410)$ & $(0.471)$ \\
\hline \multirow[t]{2}{*}{ Net wealth } & 1.289 & $2.410^{*}$ & 0.224 & 0.588 \\
\hline & (1.359) & $(1.424)$ & $(1.037)$ & $(1.250)$ \\
\hline \multirow[t]{2}{*}{ Married/cohab. } & $1.747^{* *}$ & $2.150^{* *}$ & 0.554 & $1.175^{*}$ \\
\hline & $(0.734)$ & $(0.895)$ & $(0.468)$ & $(0.639)$ \\
\hline \multirow[t]{2}{*}{ No. children (in/out) } & 0.136 & 0.165 & 0.046 & 0.060 \\
\hline & $(0.231)$ & $(0.251)$ & $(0.117)$ & $(0.135)$ \\
\hline \multirow[t]{2}{*}{ South } & $-1.747^{* *}$ & $-2.271^{* * *}$ & -0.497 & -0.737 \\
\hline & $(0.761)$ & $(0.826)$ & $(0.462)$ & $(0.530)$ \\
\hline \multirow[t]{2}{*}{ Center } & $-1.484^{* *}$ & $-1.448^{*}$ & -0.349 & -0.050 \\
\hline & $(0.690)$ & $(0.755)$ & $(0.446)$ & $(0.514)$ \\
\hline \multirow[t]{2}{*}{ Constant } & $17.364^{* * *}$ & $18.371^{* * *}$ & $15.156^{* * *}$ & $17.967^{* * *}$ \\
\hline & $(1.752)$ & $(2.331)$ & $(1.102)$ & $(1.620)$ \\
\hline
\end{tabular}

Notes: Observations: 527 aged 55-70 (399 men); 1186 aged 50-70 (848 men). Estimated coefficients are reported. Standard errors (in round brackets) are robust to heteroskedasticity. Dependent variable: desired working hours $* p<0.1 ; * * p<0.05 ; * * * p<0.01$

prevent the use of alternative routes to exit the labour market, such as disability pensions or unemployment/redundancy schemes (like the so-called Cassa Integrazione Guadagni), which are costly and affect either the public or the private budget and still are, notwithstanding changes and reforms, particularly relevant in the Italian context.

It must be acknowledged that flexibility in the working schedule generally comes at a cost for employers, particularly where older workers are concerned, which could explain why gradual retirement and part-time jobs for older workers are less developed than looking just at the individuals' labour supply would imply. This issue goes beyond 
Table 7 Desired working hours, workers aged 31-50

\begin{tabular}{|c|c|c|c|}
\hline & All & Women & Men \\
\hline \multirow[t]{2}{*}{ Male } & $2.423^{* * *}$ & & \\
\hline & $(0.288)$ & & \\
\hline \multirow[t]{2}{*}{ Hours worked } & $0.416^{* * *}$ & $0.481^{* * *}$ & $0.341^{* * *}$ \\
\hline & $(0.021)$ & $(0.029)$ & $(0.032)$ \\
\hline \multirow[t]{2}{*}{ Wage } & 0.029 & -0.032 & 0.033 \\
\hline & $(0.027)$ & $(0.062)$ & $(0.028)$ \\
\hline \multirow[t]{2}{*}{ Age $36-40$} & 0.223 & $1.117^{*}$ & -0.655 \\
\hline & $(0.388)$ & $(0.605)$ & $(0.495)$ \\
\hline \multirow[t]{2}{*}{ Age 41-45 } & $0.837^{* *}$ & $1.268^{* *}$ & 0.125 \\
\hline & $(0.383)$ & $(0.557)$ & $(0.518)$ \\
\hline \multirow[t]{2}{*}{ Age 46-50 } & 0.201 & 0.568 & -0.551 \\
\hline & $(0.378)$ & $(0.577)$ & $(0.498)$ \\
\hline \multirow[t]{2}{*}{ Medium educ. } & $0.534^{*}$ & 0.194 & $0.828^{* *}$ \\
\hline & $(0.316)$ & $(0.512)$ & $(0.383)$ \\
\hline \multirow[t]{2}{*}{ High educ. } & $-1.239^{* * *}$ & $-1.002^{*}$ & $-1.382^{* * *}$ \\
\hline & $(0.332)$ & $(0.540)$ & $(0.406)$ \\
\hline \multirow[t]{2}{*}{ Self-employed } & 0.173 & -0.163 & 0.732 \\
\hline & $(0.390)$ & $(0.628)$ & $(0.499)$ \\
\hline \multirow[t]{2}{*}{ Private sector } & $0.885^{* * *}$ & 0.531 & $1.105^{* * *}$ \\
\hline & $(0.306)$ & $(0.448)$ & $(0.417)$ \\
\hline \multirow[t]{2}{*}{ Net wealth } & 0.497 & 0.192 & 1.011 \\
\hline & $(1.164)$ & $(1.044)$ & (1.828) \\
\hline \multirow[t]{2}{*}{ Married/cohab. } & $-1.306^{* * *}$ & -1.159 & -0.676 \\
\hline & $(0.454)$ & $(0.943)$ & $(0.605)$ \\
\hline \multirow[t]{2}{*}{ No. children } & 0.017 & -0.145 & 0.164 \\
\hline & $(0.094)$ & $(0.143)$ & $(0.118)$ \\
\hline \multirow[t]{2}{*}{ Working partner } & 0.347 & -0.214 & 0.541 \\
\hline & $(0.348)$ & $(0.880)$ & $(0.389)$ \\
\hline \multirow[t]{2}{*}{ South } & -0.052 & 0.585 & -0.480 \\
\hline & $(0.340)$ & $(0.527)$ & $(0.430)$ \\
\hline \multirow[t]{2}{*}{ Center } & -0.085 & -0.103 & 0.022 \\
\hline & $(0.299)$ & $(0.464)$ & $(0.378)$ \\
\hline \multirow[t]{2}{*}{ Constant } & $18.608^{* * *}$ & $17.187^{* * *}$ & $23.581^{* * *}$ \\
\hline & $(0.897)$ & $(1.441)$ & $(1.367)$ \\
\hline
\end{tabular}

Notes: Observations: 2612 (1053 women and 1559 men). Estimated coefficients are reported. Standard errors (in round brackets) are robust to heteroskedasticity. Dependent variable: desired work $* p<0.1 ; * * p<0.05 ; * * * p<0.01$

the scope of our analysis; it is extensively discussed in Kantarci and van Soest (2008) and represents an interesting topic for future research.

\section{Endnotes}

${ }^{1}$ Female labour supply, in particular, whose dynamic is strongly affected by fertility decisions and caring responsibilities (Battistin et al. 2015; Bratti et al. 2018), might be more responsive to a smoother decline in working hours to retirement. 
${ }^{2}$ For simplicity, we do not model directly DB pension formulas which are not actuarially fair and imply that increases in the pension benefit do not compensate the forgone year of retirement and the additional year of contributions (Castellino and Fornero 2001). Their implicit taxation of pension wealth in consequence of postponement of retirement can be thought of in terms of 'unobservable' affecting the utility of working.

${ }^{3}$ We assume here that everyone retires in the next period $(R+1)$. This simplifying assumption does not alter the main message of our stylized framework.

${ }^{4}$ If, instead, $V^{w p t}>V^{w}>V^{r}$, workers may decide to switch from a full-time to a part-time working schedule.

${ }^{5}$ The sample consists of 2142 retirees and 528 workers.

${ }^{6}$ Medium-level education captures respondents with a high school diploma; highly educated respondents are those with a degree or more. The reference category is low-level education (compulsory schooling).

${ }^{7}$ One of the variables that could potentially explain less desire for work is health status, which is, however, not present in this wave of the SHIW.

${ }^{8}$ The reduced number of retirees who would like to work and indicate their desired intensity suggests some caution is required in the interpretation of these results.

${ }^{9}$ Sample size issues do not allow this equation to be estimated by gender.

\section{Acknowledgements}

This project has received funding from the European Union's Horizon 2020 research and innovation programme under the Marie Sklodowska-Curie grant agreement no. 655770 (Trucchi). We thank Marco Disarò for research assistance with macro data. We would also like to thank the anonymous referee and the editor for the useful remarks.

Responsible editor: Juan F. Jimeno

\section{Competing interests}

The IZA Journal of Labor Policy is committed to the IZA Guiding Principles of Research Integrity. The authors declare that they have observed these principles

\section{Publisher's Note}

Springer Nature remains neutral with regard to jurisdictional claims in published maps and institutional affiliations.

\footnotetext{
Author details

${ }^{1}$ Ca' Foscari University of Venice, Fondamenta San Giobbe - Cannaregio 873, 30121 Venice, Italy. ${ }^{2}$ University of Turin, CeRP-Collegio Carlo Alberto, Corso Unione Sovietica, 218 Bis, 10134 Turin, Italy. ${ }^{3}$ University of Turin, CeRP-Collegio Carlo Alberto and Netspar, Corso Unione Sovietica, 218 Bis, 10134 Turin, Italy.
}

Received: 29 January 2018 Accepted: 24 September 2018

Published online: 25 October 2018

References

Banks J, Blundell R, Rivas MC (2010) The dynamics of retirement behavior in couples: Reduced-form evidence from England and the US. In: mimeo

Battistin E, Nadai MD, Padula M (2015) Roadblocks on the Road to Grandmas House: Fertility Consequences of Delayed Retirement. Working Papers 748. Queen Mary University of London, School of Economics and Finance

Bratti M, Frattini T, Scervini F (2018) Grandparental Availability for Child Care and Maternal Employment: Pension Reform Evidence from Italy. Journal of Population Economics 31(4):1239-1277

Brown JR, Coile CC, Weisbenner SJ (2010) The effect of inheritance receipt on retirement. The Review of Economics and Statistics 92(2):425-434

Brown, S.K. (2005). Attitudes of individuals 50 and older toward phased retirement. Washington, D.C.: AARP Knowledge Management, Retrieved April 3, 2012, from http://assets.aarp.org/rgcenter/post-import/phasedret.pdf

Brunello G, Langella M (2013) Bridge jobs in Europe. IZA Journal of Labor Policy 2:11

Callan T, van Soest A, Walsh JR (2009) Tax structure and female labour supply: Evidence from Ireland. LABOUR 23(1):1-35

Castellino O, Fornero E (2001) La riforma del sistema previdenziale italiano. II Mulino.

Cesarini D, Lindqvist E, Notowidigdo MJ, Ostling R (2015) The effect of wealth on individual and household labor supply: Evidence from Swedish lotteries. American Economic Review 17(12):3917-3946

Coda Moscarola F, Fornero E, Strom S (2016) Absenteeism, childcare and the effectiveness of pension reforms. IZA Journal of European Labor Studies 5(1):1-18

Delsen L (1996) Gradual retirement: Lessons from the Nordic countries and the Netherlands. European Journal of Industrial Relations 2(1):55-67 
Devicienti F, Grinza E, Manello A and D. Vannoni (2016). The Impact of Part-Time Work on Firm Total Factor Productivity: Evidence from Italy. Discussion Paper 10314. IZA.

Eurofound (2016). Extending working lives through flexible retirement schemes: Partial retirement. Technical report, Publications Office of the European Union, Luxembourg.

European Commission (2015). The 2015 Pension Adequacy Report: current and future income adequacy in old age in the EU. Technical report, Directorate-General for Employment, Social Affairs and Inclusion.

Euwals R, van Soest A (1999) Desired and actual labour supply of unmarried men and women in the Netherlands. Labour Economics 6(1):95-118

Kantarci T, Van Soest A (2008) Gradual retirement: Preferences and limitations. De Economist 156(2):113-144

OECD (2016). Pensions at a glance.

Peri G, Romiti A, Rossi M (2015) Immigrants, domestic labor and women's retirement decisions. Labour Economics 36:18-34

Picchio M, Suetens S, van Ours JC (2017) Labour supply effects of winning a lottery. Economic Journal 128:1700-1729

Stancanelli E, Van Soest A (2012) Retirement and home production: A regression discontinuity approach. American Economic Review 102(3):600-605

Stark O, Nicinska A (2015) How Inheriting Affects Bequest Plans. Economica 82:1126-1152

van Soest A, Das M, Gong X (2002) A structural labour supply model with flxible preferences. Journal of Econometrics 107(1-2): $345-374$

van Soest A, Vonkova H (2014) How sensitive are retirement decisions to financial incentives? A stated preference analysis. Journal of Applied Econometrics 29(2):246-264

Submit your manuscript to a SpringerOpen ${ }^{\circ}$ journal and benefit from:

- Convenient online submission

- Rigorous peer review

- Open access: articles freely available online

High visibility within the field

Retaining the copyright to your article

Submit your next manuscript at $>$ springeropen.com 